\title{
Modeling the impact of delaying surgery for early esophageal cancer in the era of COVID-19
}

\author{
Maren E. Shipe ${ }^{1}$ ] J Jordan J. Baechle ${ }^{2}$ Stephen A. Deppen ${ }^{3,4}$ Erin A. Gillaspie ${ }^{4}$ Eric L. Grogan 3,4
}

Received: 5 June 2020 / Accepted: 15 October 2020 / Published online: 2 November 2020

( ) This is a U.S. government work and not under copyright protection in the U.S.; foreign copyright protection may apply 2020

\begin{abstract}
Background Surgical society guidelines have recommended changing the treatment strategy for early esophageal cancer during the novel coronavirus (COVID-19) pandemic. Delaying resection can allow for interim disease progression, but the impact of this delay on mortality is unknown. The COVID-19 infection rate at which immediate operative risk exceeds benefit is unknown. We sought to model immediate versus delayed surgical resection in a T1b esophageal adenocarcinoma. Methods A decision analysis model was developed, and sensitivity analyses performed. The base case was a 65 -year-old male smoker presenting with cT1b esophageal adenocarcinoma scheduled for esophagectomy during the COVID-19 pandemic. We compared immediate surgical resection to delayed resection after 3 months. The likelihood of key outcomes was derived from the literature where available. The outcome was 5-year overall survival.

Results Proceeding with immediate esophagectomy for the base case scenario resulted in slightly improved 5-year overall survival when compared to delaying surgery by 3 months (5-year overall survival 0.74 for immediate and 0.73 for delayed resection). In sensitivity analyses, a delayed approach became preferred when the probability of perioperative COVID-19 infection increased above $7 \%$.

Conclusions Immediate resection of early esophageal cancer during the COVID-19 pandemic did not decrease 5-year survival when compared to resection after 3 months for the base case scenario. However, as the risk of perioperative COVID19 infection increases above 7\%, a delayed approach has improved 5-year survival. This balance should be frequently re-examined by surgeons as infection risk changes in each hospital and community throughout the COVID-19 pandemic.
\end{abstract}

Keywords Esophageal cancer · Coronavirus $\cdot$ COVID-19 $\cdot$ Decision analysis model $\cdot$ Risk modeling

The novel coronavirus disease 2019 (COVID-19) is a global pandemic caused by severe acute respiratory syndrome coronavirus 2 (SARS-CoV-2) [1, 2]. The clinical spectrum of COVID-19 infection ranges from asymptomatic to respiratory failure requiring hospitalization and even death $[1,3]$. Across the globe, healthcare resources have been

Eric L. Grogan

eric.grogan@vumc.org

1 Department of General Surgery, Vanderbilt University Medical Center, Nashville, TN, USA

2 School of Medicine, Meharry Medical College, Nashville, TN, USA

3 Department of Surgery, Tennessee Valley Healthcare System, Nashville, TN, USA

4 Department of Thoracic Surgery, Vanderbilt University Medical Center, 609 Oxford House, 1313 21st Ave. South, Nashville, TN 37232, USA diverted to combat the novel disease and the usual care of cancer patients has been disrupted. High rates of hospital-acquired COVID-19 infections in patients admitted for cancer care have been reported in regions with a high prevalence of coronavirus [4-6]. These patients exhibit a particularly severe clinical course with high mortality rate $[4,7,8]$. Weighing the risk of cancer progression due to delayed care against the risk of COVID-19 infection poses a clinical dilemma for surgeons and patients.

The American College of Surgeons Commission on Cancer, The Society of Thoracic Surgeons and the American Association of Thoracic Surgery established COVID-19 guidelines to help triage patients with resectable thoracic malignancies based on consensus expert opinion $[9,10]$. These guidelines were created to aid surgeons in deciding whether to proceed with usual clinical care (such as an immediate resection of early esophageal cancer), to delay treatment until the prevalence of COVID-19 and the strain 
on resources has decreased, or to consider alternative therapies (such as neoadjuvant treatment or endoscopic resection). The guidelines for esophageal adenocarcinoma suggest expedient resection by endoscopic approach for superficial disease or surgical resection of clinical stage $\mathrm{T} 1 \mathrm{~b}$ and above during the Phase I response. However, during Phase 2 delaying surgery is recommended for all stages until the COVID19 burden has decreased [9]. As COVID-19 prevalence spikes and declines in different communities healthcare centers are forced to start and stop non-emergent surgeries such as esophageal resections without data-driven guidelines.

Esophageal cancer is common, ranking seventh in incidence and sixth in mortality worldwide [11]. In the United States, only $20 \%$ of patients present with early stage disease. The depth of tumor invasion has been established as the most influential risk factor for nodal involvement [12, 13]. Patients with early stage esophageal cancer without nodal involvement have a $>80 \% 5$-year overall survival compared to $<25 \%$ for patients with nodal involvement [14-16]. A delay in therapy for esophageal adenocarcinoma could result in a drastic reduction in survival.

Surgeons must weigh the risk of esophageal cancer progression secondary to delayed resection against the risk of morbidity and mortality from the COVID-19 infection. This issue will remain important as COVID-19 prevalence fluctuates across the country. The primary aim of this study was to model the optimal management strategy by comparing immediate versus delayed surgical resection in a cT1b esophageal adenocarcinoma during the COVID-19 pandemic.

\section{Materials and methods}

\section{Decision model design}

We developed a decision analysis model to evaluate two treatment strategies for an early esophageal cancer during the COVID-19 pandemic: immediate esophagectomy or delayed esophagectomy after 3 months (Fig. 1). The decision tree details the initial choice (the decision node) of immediate or delayed resection and follows branch points to the ultimate outcomes of death or 5-year overall survival (terminal nodes). Each operative subtree has chance nodes for operative mortality, perioperative COVID-19 infection, and mortality due to COVID-19. Finally, under the delayed resection choice there is a third option at the first chance node: no surgery due to disease progression in the interim (see below).

We used TreeAge Pro version 2018 (TreeAge Software, Inc., Williamson, MA) to construct the decision tree model. The literature review and expert opinion (when published data was not available) were used to estimate model parameters and ranges for sensitivity analysis. As no human or animal subjects were involved in this project, institutional review board approval and informed consent were not required.

\section{Patients}

Our base clinical case was a 65 -year-old male smoker with a $20 \mathrm{~mm}$ cT1b middle esophageal adenocarcinoma. An early stage esophageal adenocarcinoma was chosen for modeling due to the equipoise in society recommendations for treatment of these patients during the COVID-19 pandemic. He had negative preoperative COVID-19 testing. The patient was a candidate for esophagectomy and presented to a hospital during the acute phase of the COVID-19 pandemic. This assumes the presence of COVID-19 in the community and hospital, but not to a degree that hospital resources are exhausted, the institution still has ICU vent capacity and the COVID trajectory is not in the rapid escalation phase.

\section{Treatment strategies}

Treatment simulations were performed for both immediate and delayed resection via minimally invasive or open transhiatal esophagectomy. Assumptions for patients undergoing immediate surgery were a 7-10 days hospitalization [17-20], during which time the patient would be at risk for a COVID-19 infection.

Patients undergoing a delayed resection at 3 months did not undergo interval therapy (neoadjuvant chemotherapy or radiation). Each patient was restaged with imaging prior to surgery to rule out progression; those with clinical stage I or II proceeded with standard operative therapy while those exhibiting progression (stage III or IV) followed a different branch point in the decision analysis (Fig. 1 and Table 1). The COVID-19 prevalence in the community and thus hospital burden was assumed to have decreased to almost zero.

Surgical morbidity was assumed to be identical in immediate or delayed surgery and thus not influenced by the decision to delay. Therefore, they were omitted from the model. Operative mortality was assumed to be equal for immediate or delayed esophagectomy but was included in the model to allow for sensitivity analyses [21-23].

\section{Model variables}

\section{Esophageal cancer}

The distribution of pathologic stages determined at the time of surgery for a patient with clinical T1b esophageal adenocarcinoma were derived from the literature (Table 1) [24-29]. The distribution of esophageal 


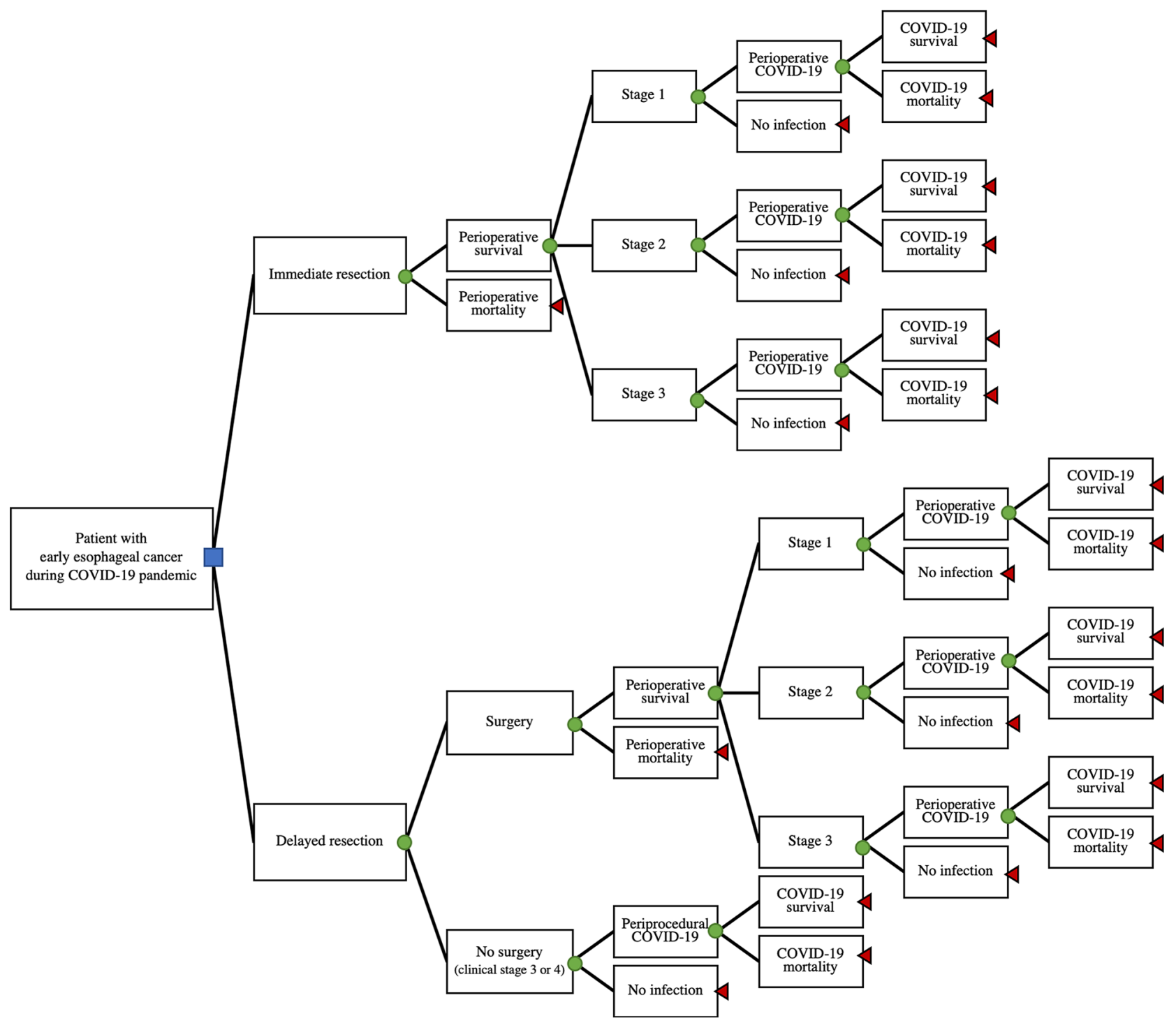

Fig. 1 Decision analysis tree for timing of esophagectomy for patient with cT1b esophageal adenocarcinoma during COVID-19 pandemic. Blue square: decision node, whether to choose immediate or delayed surgical resection. Green circles: chance nodes. Red triangles: terminal nodes (Color figure online)

a patient's probability of advanced disease increases, so does their probability of mortality (see below).

\section{COVID-19}

The COVID-19 parameters (Table 1) were derived from the limited published reports available as of April 15, 2020. International reports of the risk of in-hospital COVID-19 exposure reported is much higher than community exposure rates (estimated to be $1-40 \%$ of cases) $[3,4$, 31], but this has not been our domestic experience, where the community rate exceeds the hospital rate [32]. Thus, we created one variable, perioperative COVID-19 infection, 
Table 1 Model parameters

\begin{tabular}{llll}
\hline Chance parameter & Probability & $\begin{array}{l}\text { Values for sensitivity } \\
\text { analysis }\end{array}$ & Reference(s) \\
\hline Operative mortality & 0.047 & $0.023-0.071$ & {$[21-23]$} \\
COVID-19 mortality & 0.25 & $0.150-0.520$ & {$[4,31,33,34]$} \\
Immediate resection & & & \\
COVID-19 infection & 0.014 & $0.0001-0.100$ & $*$ \\
Stage 1 & 0.93 & $0.817-0.895$ & {$[24,25]$} \\
Stage 2 & 0.06 & $0.107-0.143$ & {$[24,25]$} \\
Stage 3 & 0.01 & $0.005-0.034$ & {$[24,25]$} \\
Delayed resection & & & $*$ \\
COVID-19 infection & 0.00001 & 0.01 & {$[24]$} \\
Surgery & 0.994 & $0.95-1.0$ & {$[26-29]$} \\
Stage 1 & 0.91 & $0.789-0.895$ & {$[26-29]$} \\
Stage 2 & 0.07 & $0.111-0.200$ & {$[26-29]$} \\
Stage 3 & 0.02 & $0.005-0.038$ & {$[24]$} \\
No surgery (disease progression) & 0.006 & $0-0.05$ & \\
\hline
\end{tabular}

*Parameters set by research team based on base case clinical scenario, current local data

that encompasses the risk to patients of both communityacquired and hospital-acquired infection around surgery. The risk of perioperative COVID-19 infection for our base case undergoing immediate surgery was set at $1.4 \%$ by the research team to reflect the local prevalence of disease.

For the delayed esophagectomy, the risk of perioperative COVID-19 exposure was set to almost zero as the purpose of delaying surgery 3 months was to allow the prevalence to decrease. All delayed patients are at risk for community infection during the delay as well as hospital-acquired infection during re-staging and any recommended therapy—surgery in those not exhibiting progression or port placement and chemotherapy in those who do.

The risk of COVID-19-related mortality after esophagectomy was derived from reports of hospitalized or institutionalized patients with any type of cancer or other significant comorbidities, which contributed to a more virulent infection and higher acuity disease [4, 31, 33, 34]. We felt these estimates appropriately reflected risk in esophageal patients because of their cancer diagnosis and high prevalence of post-operative pulmonary [35]. The probability of mortality is higher than in the general population of 60-69-year-old patients, which was deemed appropriate for our base case.

\section{Five-year overall survival}

The 5-year overall survival for esophageal adenocarcinoma by pathological stage was established from the literature (Table 2). Progression data for each stage was limited, therefore we used averaged 5-year overall survival data for the substages as an aggregate for stage I-IV disease.

As COVID-19 is a new disease emerging in late 2019 there is no long-term follow up of patients available for
Table 2 5-year overall survival

\begin{tabular}{llll}
\hline 5-year overall survival & Value & $\begin{array}{l}\text { Values for sensi- } \\
\text { tivity analysis }\end{array}$ & Reference(s) \\
\hline \multicolumn{4}{l}{ Without COVID-19 infection } \\
Post-op, stage 1 & 0.81 & $0.73-0.88$ & {$[15,37]$} \\
Post-op, stage 2 & 0.48 & $0.4-0.55$ & {$[15,37]$} \\
Post-op, stage 3 & 0.15 & $0.031-0.24$ & {$[15,37]$} \\
Non-op, stage 3 or 4 & 0.08 & $0.02-0.12$ & {$[15,37]$} \\
With post-operative COVID-19 infection & \\
Post-op, stage 1 & 0.59 & $0.54-0.64$ & {$[15,36]$} \\
Post-op, stage 2 & 0.35 & $0.29-0.49$ & {$[15,36]$} \\
Post-op, stage 3 & 0.11 & $0.029-0.18$ & {$[15,36]$} \\
Non-op, stage 3 or 4 & 0.06 & $0.0001-0.07$ & {$[15,36]$} \\
\hline
\end{tabular}

reference. To approximate the effect of COVID-19 on overall survival after esophagectomy, we utilized available data on the impact of significant pulmonary complications after esophagectomy on 5-year overall survival $[15,36]$. The decrease in 5-year overall survival due to COVID-19 was set at 0.26 (range 0.1-0.35), and this was used to discount the cancer-related survival for each stage. In other words, if the patient had pathologic stage I esophageal cancer but contracted and survived a perioperative COVID-19 infection, his likelihood of surviving 5-years would decrease from 81 to $59 \%$.

\section{Sensitivity analyses}

One-way sensitivity analyses were performed to account for uncertainty in key model parameters (Tables 1 and 2) and to approximate how differences in the base case could 
affect the model outcome. This is accomplished by altering one parameter at a time while holding all other variables constant at baseline values. These analyses included varying the stage progression of esophageal adenocarcinoma with the delay, the 5-year overall survival of esophageal adenocarcinoma by stage, the probability of perioperative COVID-19 infection, and the probability of mortality from COVID-19. Two-way sensitivity analysis was performed by simultaneously varying the probability of perioperative COVID-19 infection and COVID-19-related mortality while holding all other parameters constant.

\section{Results}

For the base case scenario, proceeding with immediate resection of a cT1b esophageal adenocarcinoma resulted in slightly improved 5-year overall survival when compared to delaying by 3 months to allow for COVID-19 prevalence to decrease from $1.4 \%$ to almost zero (5-year overall survival 0.74 for immediate and 0.73 for delayed resection).

\section{Sensitivity analyses}

Altering the probability of malignancy or the mortality attributed to each stage of esophageal adenocarcinoma did not change the outcome of favoring immediate esophagectomy. If the model was altered to have decreased stage progression after the 3 -month delay ( $1 \%$ change in pathologic stage 1 progression rather than $2 \%$ ), then the timing of resection was equivocal (0.74). If the probability of perioperative COVID-19 infection was increased to between 4 and $6 \%$ then the two choices are equivocal (0.73). If the probability of infection exceeded $7 \%$ then delayed resection is increasingly favored.

The two-way sensitivity analysis results are presented in Fig. 2. Delayed resection was increasingly preferred as the probability of either perioperative infection or mortality from COVID-19 are increased. For example, delayed resection was preferred if mortality is $>10 \%$ and infection risk is $>8 \%$. Similarly, delayed resection was preferred if mortality is $>50 \%$ and infection is $>5 \%$.

\section{Discussion}

Triaging the care of patients requiring non-emergent surgeries during a new infectious disease pandemic presents a new challenge to surgeons of all specialties. Hospitals must balance the consumption of resources potentially needed for COVID patients with the potential harm to cancer patients if operations are delayed. As survival from esophageal cancer precipitously decreases with stage progression $[15,36$, 37], we created a simple and informative model to estimate the potential harm to a patient with an early stage $\mathrm{cT} 1 \mathrm{~b}$

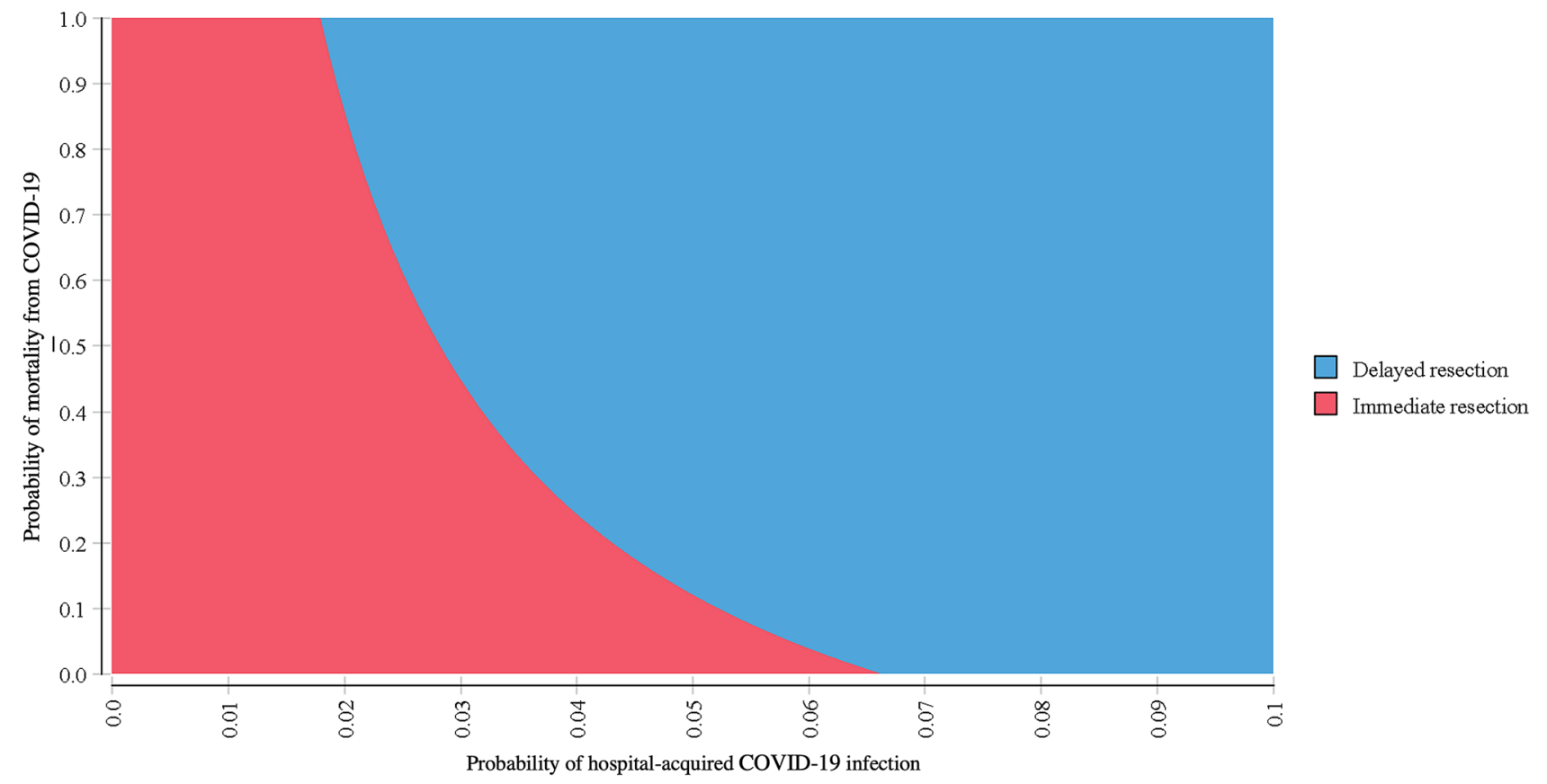

Fig. 2 Two-way sensitivity analysis for probability of infection and mortality from COVID-19. Graph displays the favored strategy (immediate or delayed resection) across a range of possible periop- erative COVID-19 infection and COVID-19-related mortality probabilities while holding all other model variables constant at baseline values (color figure online) 
esophageal adenocarcinoma if his care was delayed due to the COVID-19 pandemic.

Our decision analysis model found that delaying resection for 3 months would likely impact 5-year overall survival, though not significantly ( 0.73 vs. 0.74 for immediate esophagectomy). The model was strongly impacted by the probability of COVID-19 infection as well as the resultant morbidity and mortality. If either of these parameters increased significantly, the model favored delaying resection to theoretically allow for COVID-19 burden to decrease. For example, if the risk of perioperative COVID19 infection exceeded 7\%, a patient undergoing an immediate esophagectomy could have worse survival than with a delayed operation.

The decrease in COVID-19 prevalence at 3 months assumes the success of public health measures such as social distancing, widely available testing and contract tracing. Otherwise, a 3-month delay will carry both risk of disease progression as well as risk of COVID-19 infection. A probability of infection of nearly zero after the delay seems unlikely to occur at this point in the pandemic, but it was chosen for the base case scenario as the ideal outcome. We modeled higher probabilities of infection after the delay and as the probability of infection increased, proceeding immediately with surgery was even more strongly favored. However, while higher rates of COVID-19 after a 3-month delay did not impact the overall outcome of the model, it could impact the resources available for non-emergent surgeries. Hospitals must be equipped to handle not only a surge in patients with COVID-19, but also post-operative patients with or without complications such as prolonged ventilation and intensive care stays.

While the decision analysis model parameters are very narrow in scope by design, the sensitivity analyses allow for modeling a range of uncertainty. The two-way sensitivity analysis, for example, can allow clinicians to adapt the results to different patient- or community-level factors. If a patient presents who is younger and healthier than our base case, he would likely be at a lower risk for both COVID-19 infection and mortality. Using Fig. 2, if the probability of infection is set at $1 \%$ and the mortality at $5 \%$, then immediate resection is favored. Conversely, an older patient with multiple comorbidities who is at higher risk of COVID-19 complications can be approximated setting the probability of infection at $10 \%$ and mortality at $60 \%$. This would strongly favor delaying resection until COVID-19 prevalence has decreased in the community.

This study had several limitations. First, the paucity of literature available on COVID-19 resulted in estimating several model parameters from similar but non-identical clinical scenarios. We addressed this by analyzing a wide range of values for the COVID-19 parameters in our sensitivity analyses. Secondly, we did not model community-acquired COVID-19 infection separately from hospital-acquired COVID-19. While hospital-acquired infection seemed to drive the epidemic in China, we have not had the same experience thus far in the pandemic, but significant differences between these two infection rates could impact the outcome of the model. Finally, we did not account for surgical complications in the model. While the probability should be nearly equivalent between the two strategies, if there was a predominance in one arm it would likely have a significant impact on the probability of COVID-19 infection and mortality.

Despite these limitations, we believe this simplified model provided a robust framework to inform the surgical decision and was more adaptable for other, similar operative triaging decisions during the COVID-19 pandemic. This model should be easily adaptable as COVID-19 prevalence ebbs and surges in different communities, and if other infectious pandemics emerge posing similar dilemmas to surgeons.

\section{Conclusion}

Proceeding with immediate esophagectomy for early esophageal adenocarcinoma during the COVID-19 pandemic resulted in a similar but slightly improved 5-year overall survival when compared to resection after a 3 -month delay in our base case scenario. However, as the risk of infection with COVID-19 increased above 7\%, delaying operations for 3 months has an improved longterm survival. This balance should be frequently re-examined at each healthcare facility based on local COVID-19 prevalence throughout the curve of the pandemic.

Acknowledgements Dr. Shipe is supported by the Agency for Healthcare Research and Quality (AHRQ) under Award Number T32 HS026122. Dr. Grogan's research time is supported by the Department of Veterans Affairs. The views expressed in this article are those of the authors and do not necessarily represent the views of the Department of Veterans Affairs. Dr. Deppen has support from the Early Detection Research Network NCI-5U24-CA0866368. The funding agency had no role in the design and conduct of the study; collection, management, analysis, and interpretation of the data; the preparation, review, or approval of the manuscript; or in the decision to submit the manuscript for publication.

Author contributions Model development: MES, SAD, ELG. Parameter development: MES, JJB. Manuscript: MES, JJB, SAD, EAG, ELG.

Funding Dr. Shipe: Agency for Healthcare Research and Quality (AHRQ) Award Number T32 HS026122. Dr. Grogan: Department of Veterans Affairs. Dr. Deppen Early Detection Research Network NCI-5U24-CA0866368. 


\section{Compliance with ethical standards}

Disclosures Maren E. Shipe, Jordan J. Baechle, Stephen A. Deppen, Erin A. Gillaspie, and Eric L. Grogan have no conflicts of interest or financial ties to disclose.

\section{References}

1. Li Q, Guan X, Wu P, Wang X, Zhou L, Tong Y, Ren R, Leung KSM, Lau EHY, Wong JY, Xing X, Xiang N, Wu Y, Li C, Chen Q, Li D, Liu T, Zhao J, Liu M, Tu W, Chen C, Jin L, Yang R, Wang Q, Zhou S, Wang R, Liu H, Luo Y, Liu Y, Shao G, Li H, Tao Z, Yang Y, Deng Z, Liu B, Ma Z, Zhang Y, Shi G, Lam TTY, Wu JT, Gao GF, Cowling BJ, Yang B, Leung GM, Feng Z (2020) Early transmission dynamics in Wuhan, China, of novel coronavirus-infected pneumonia. N Engl J Med 382(13):1199-1207. https ://doi.org/10.1056/NEJMoa2001316

2. WHO. Coronavirus (COVID-19) events as they happen. World Health Organization. https://www.who.int/emergencies/diseases/ novel-coronavirus-2019/events-as-they-happen. Accessed 6 Apr 2020

3. Wang D, Hu B, Hu C, Zhu F, Liu X, Zhang J, Wang B, Xiang H, Cheng Z, Xiong Y, Zhao Y, Li Y, Wang X, Peng Z (2020) Clinical characteristics of 138 hospitalized patients with 2019 novel coronavirus-infected pneumonia in Wuhan, China. JAMA J Am Med Assoc 323(11):1061-1069. https://doi.org/10.1001/ jama.2020.1585

4. Yu J, Ouyang W, Chua MLK, Xie C (2020) SARS-CoV-2 transmission in patients with cancer at a tertiary care hospital in Wuhan, China. JAMA Oncol. https://doi.org/10.1001/jamao ncol.2020.0980

5. Wang Z, Wang J, He J (2020) Active and effective measures for the care of patients with cancer during the COVID-19 spread in China. JAMA Oncol. https://doi.org/10.1001/jamao ncol.2020.1198

6. Dai M, Liu D, Liu M, Zhou F, Li G, Chen Z, Zhang Z, You H, Wu M, Zheng Q, Xiong Y, Xiong H, Wang C, Chen C, Xiong F, Zhang Y, Peng Y, Ge S, Zhen B, Yu T, Wang L, Wang H, Liu Y, Chen Y, Mei J, Gao X, Li Z, Gan L, He C, Li Z, Shi Y, Qi Y, Yang J, Tenen DG, Chai L, Mucci LA, Santillana M, Cai H (2020) Patients with cancer appear more vulnerable to SARS-COV-2: a multi-center study during the COVID-19 outbreak. Cancer Discov. https://doi.org/10.1158/2159-8290.CD-20-0422

7. Liang W, Guan W, Chen R, Wang W, Li J, Xu K, Li C, Ai Q, Lu W, Liang H, Li S, He J (2020) Cancer patients in SARSCoV-2 infection: a nationwide analysis in China. Lancet Oncol 21(3):335-337. https://doi.org/10.1016/S1470-2045(20)30096-6

8. Xia Y, Jin R, Zhao J, Li W, Shen H (2020) Risk of COVID-19 for patients with cancer. Lancet Oncol 21(4):e180. https://doi. org/10.1016/S1470-2045(20)30150-9

9. American College of Surgeons. COVID-19 Guidelines for Triage of Thoracic Patients. American College of Surgeons Commission on Cancer. https://www.facs.org/covid-19/clinical-guidance/elect ive-case/thoracic-cancer. Accessed 7 Apr 2020

10. Wiener RS, Gould MK, Arenberg DA, Au DH, Fennig K, Lamb CR, Mazzone PJ, Midthun DE, Napoli M, Ost DE, Powell CA, Rivera MP, Slatore CG, Tanner NT, Vachani A, Wisnivesky JP, Yoon SH, Black WC, Detterbeck F, Hirschowitz E, Jett J, Kinsinger L (2015) An official American Thoracic Society/American College of Chest Physicians policy statement: implementation of low-dose computed tomography lung cancer screening programs in clinical practice. Am J Respir Crit Care Med 192(7):881-891. https://doi.org/10.1164/rccm.201508-1671ST
11. Bray F, Ferlay J, Soerjomataram I, Siegel RL, Torre LA, Jemal A (2018) Global cancer statistics 2018: GLOBOCAN estimates of incidence and mortality worldwide for 36 cancers in 185 countries. CA Cancer J Clin 68(6):394-424. https://doi.org/10.3322/ caac. 21492

12. Brown CS, Gwilliam N, Kyrillos A, Lutfi W, Lapin B, Kim KW, Krantz SB, Howington JA, Yao K, Ujiki MB (2018) Predictors of pathologic upstaging in early esophageal adenocarcinoma: results from the National Cancer Database. Am J Surg 216(1):124-130. https://doi.org/10.1016/j.amjsurg.2017.07.015

13. Zhang X, Wang Y, Qu P, Liu-Helmersson J, Zhao L, Zhang L, Sang S (2018) Prognostic value of tumor length for causespecific death in resectable esophageal cancer. Ann Thorac Surg 106(4):1038-1046. https://doi.org/10.1016/j.athoracsur .2018.05.018

14. Rice TW, Patil DT, Blackstone EH (2017) 8th edition AJCC/ UICC staging of cancers of the esophagus and esophagogastric junction: application to clinical practice. Ann Cardiothorac Surg 6(2):119-130. https://doi.org/10.21037/acs.2017.03.14

15. Talsma K, Van Hagen P, Grotenhuis BA, Steyerberg EW, Tilanus HW, Van Lanschot JJB, Wijnhoven BPL (2012) Comparison of the 6th and 7th editions of the UICC-AJCC TNM classification for esophageal cancer. Ann Surg Oncol 19(7):2142-2148. https ://doi.org/10.1245/s10434-012-2218-5

16. National Cancer Institute. SEER Stat Fact Sheets: Esophageal Cancer. National Cancer Institute. https://seer.cancer.gov/statf acts/html/esoph.html. Published 2016. Accessed 6 Apr 2020

17. Sun F, Chen T, Han J, Ye P, Hu J (2015) Staging accuracy of endoscopic ultrasound for esophageal cancer after neoadjuvant chemotherapy: a meta-analysis and systematic review. Dis Esophagus 28(8):757-771. https://doi.org/10.1111/dote.12274

18. Sgourakis G, Gockel I, Lang H (2013) Endoscopic and surgical resection of T1a/T1b esophageal neoplasms: a systematic review. World J Gastroenterol 19(9):1424-1437. https://doi.org/10.3748/ wjg.v19.19.1424

19. Mitzman B, Lutfi W, Wang CH, Krantz S, Howington JA, Kim KW (2017) Minimally invasive esophagectomy provides equivalent survival to open esophagectomy: an analysis of the National Cancer Database. Semin Thorac Cardiovasc Surg 29(2):244-253. https://doi.org/10.1053/j.semtcvs.2017.03.007

20. Giwa F, Salami A, Abioye AI (2018) Hospital esophagectomy volume and postoperative length of stay: a systematic review and meta-analysis. Am J Surg 215(1):155-162. https://doi. org/10.1016/j.amjsurg.2017.03.022

21. Schlottmann F, Strassle PD, Patti MG (2017) Transhiatal vs. transthoracic esophagectomy: a NSQIP analysis of postoperative outcomes and risk factors for morbidity. J Gastrointest Surg 21(11):1757-1763. https://doi.org/10.1007/s11605-017-3572-1

22. Khullar OV, Jiang R, Force SD, Pickens A, Sancheti MS, Ward K, Gillespie T, Fernandez FG (2015) Transthoracic versus transhiatal resection for esophageal adenocarcinoma of the lower esophagus: a value-based comparison. J Surg Oncol 112(5):517-523. https:// doi.org/10.1002/jso. 24024

23. Haisley KR, Abdelmoaty WF, Dunst CM (2020) Laparoscopic transhiatal esophagectomy for invasive esophageal adenocarcinoma. J Gastrointest Surg. https://doi.org/10.1007/s11605-01904506-4

24. Shin S, Kim HK, Choi YS, Kim K, Shim YM (2014) Clinical stage T1-T2N0M0 oesophageal cancer: accuracy of clinical staging and predictive factors for lymph node metastasis. Eur J CardioThorac Surg 46(2):274-279

25. Pech O, Günter E, Dusemund F, Origer J, Lorenz D, Ell C (2010) Accuracy of endoscopic ultrasound in preoperative staging of esophageal cancer: results from a referral center for early esophageal cancer. Endoscopy 42(6):456-461. https://doi. org/10.1055/s-0029-1244022 
26. Guanrei Y, He H, Sungliang Q, Yuming C (1982) Endoscopic diagnosis of 115 cases of early esophageal carcinoma. Endoscopy 14(5):157-161. https://doi.org/10.1055/s-2007-1021608

27. Takagi I, Karasawa K (1982) Growth of squamous cell esophageal carcinoma observed by serial esophagographies. J Surg Oncol 21(1):57-60. https://doi.org/10.1002/jso.2930210115

28. Weksler B, Kennedy KF, Sullivan JL (2017) Using the National Cancer Database to create a scoring system that identifies patients with early-stage esophageal cancer at risk for nodal metastases. J Thorac Cardiovasc Surg 154(5):1787-1793. https://doi. org/10.1016/j.jtcvs.2017.07.036

29. Nabeya K, Hanaoka T, Onozawa K, Ri S, Nyumura T, Kaku C (1990) Early diagnosis of esophageal cancer. Hepatogastroenterology 37(4):368-370

30. Guan W, Liang W, Zhao Y, Liang H, Chen Z, Li Y, Liu X, Chen R, Tang C, Wang T, Ou C, Li L, Chen P, Sang L, Wang W, Li J, Li C, Ou L, Cheng B, Xiong S, Ni Z, Xiang J, Hu Y, Liu L, Shan H, Lei C, Peng Y, Wei L, Liu Y, Hu Y, Peng P, Wang J, Liu J, Chen Z, Li G, Zheng Z, Qiu S, Luo J, Ye C, Zhu S, Cheng L, Ye F, Li S, Zheng J, Zhang N, Zhong N, He J (2020) Comorbidity and its impact on 1590 patients with Covid-19 in China: a nationwide analysis. Eur Respir J. https://doi.org/10.1183/13993003.00547 $-2020$

31. Wu C, Chen X, Cai Y, Xia J, Zhou X, Xu S, Huang H, Zhang L, Zhou X, Du C, Zhang Y, Song J, Wang S, Chao Y, Yang Z, Xu J, Zhou X, Chen D, Xiong W, Xu L, Zhou F, Jiang J, Bai C, Zheng J, Song Y (2020) Risk factors associated with acute respiratory distress syndrome and death in patients with coronavirus disease 2019 pneumonia in Wuhan, China. JAMA Intern Med. https://doi. org/10.1001/jamainternmed.2020.0994

32. Tennessee Department of Health. Coronavirus Disease (COVID19), Cases by County. https://www.tn.gov/health/cedep/ncov.html. Published 2020. Accessed 25 Apr 2020
33. Arentz M, Yim E, Klaff L, Lokhandwala S, Riedo FX, Chong M, Lee M (2020) Characteristics and outcomes of 21 critically ill patients with COVID-19 in Washington State. JAMA 4720:2019 2021. https://doi.org/10.1001/jama.2020.4326

34. Sterpetti AV (2020) Lessons learned during the COVID-19 virus pandemic. J Am Coll Surg 230(6):1092-1093. https://doi. org/10.1016/j.jamcollsurg.2020.03.018

35. Yibulayin W, Abulizi S, Lv H, Sun W (2016) Minimally invasive oesophagectomy versus open esophagectomy for resectable esophageal cancer: a meta-analysis. World J Surg Oncol 14(1):304. https ://doi.org/10.1186/s12957-016-1062-7

36. Tamagawa A, Aoyama T, Tamagawa H, Ju M, Komori K, Maezawa Y, Kano K, Kazama K, Murakawa M, Atsumi Y, Sawazaki S, Hara K, Numata M, Sato T, Yukawa N, Masuda M, Rino Y (2019) Influence of postoperative pneumonia on esophageal cancer survival and recurrence. Anticancer Res 39(5):2671-2678. https://doi.org/10.21873/anticanres.13392

37. Otaki F, Ma GK, Krigel A, Dierkhising RA, Lewis JT, Blevins CH, Gopalakrishnan NP, Ravindran A, Johnson ML, Leggett CL, Wigle D, Wang KK, Falk GW, Abrams JA, Nakagawa H, Rustgi AK, Wang TC, Lightdale CJ, Ginsberg GG, Iyer GP (2020) Outcomes of patients with submucosal (T1b) esophageal adenocarcinoma: a multicenter cohort study. Gastrointest Endosc. https:// doi.org/10.1016/j.gie.2020.01.013

Publisher's Note Springer Nature remains neutral with regard to jurisdictional claims in published maps and institutional affiliations. 